\title{
METAMORFOSE DA POBREZA NO BRASIL
}

O estudo aborda o comportamento recente do governo federal no que toca ao do gasto social, procurando investigar o seu crescimento ou a estagnação em termos reais e per capita no período de 2001 a 2005. Da mesma forma, busca-se considerar o possível impacto do gasto social sobre o nível geral de emprego e a desigualdade da renda do trabalho no Brasil entre os anos de 1995 e 2004.

\section{Metamorphosis of poverty in Brazil}

The study addresses the recent behaviour of the federal government (1989-2005) for social expenditure, seeking to investigate its growth or stagnation in real terms per inhabitant. It also seeks to estimate the possible impact of social expenditure on the general level of employment and on the inequality in incomes in Brazil.

\section{Métamorphose de la pauvreté au Brésil}

L'étude aborde le comportement récent du gouvernement fédéral (1989-2005) au niveau des dépenses sociales, notamment en ce qui concerne une éventuelle croissance ou stagnation en termes réels et par habitant. De la même manière, elle cherche à estimer l'impact possible des dépenses sociales sur le niveau général de l'emploi et sur l'inégalité des revenus du travail au Brésil.

A pobreza tornou-se um tema importante na agenda dos debates não apenas no Brasil. Mas na grande maioria das vezes, a discussão sobre a pobreza ocorre fundamentalmente voltada para o registro de sua tendência de queda verificada no país e as suas razões explicativas. Poucas vezes, no entanto, concedese atenção devida ao entendimento a respeito das mudanças em curso da pobreza no Brasil. De um lado, o aparecimento de uma nova forma de reprodução da pobreza, cada vez mais concentrada no segmento da população que se encontra ativa no interior do mercado de trabalho (desempregados e ocupação precária). No passado, a situação de pobreza relacionava-se mais com o segmento inativo da população (crianças, idosos, doentes, portadores de necessidades especiais, entre outros). Assim, ter acesso à ocupação era condição quase que suficiente para superar a pobreza absoluta. De outro, a desaceleração no ritmo de redução da pobreza no Brasil a partir da década de 1980. Toda a vez que o país registra baixo desempenho econômico, as condições gerais de redução da pobreza tornamse mais frágeis. Por conta disso, o presente estudo busca destacar as principais mudanças mais recentes na pobreza brasileira. Para isso, trata inicialmente de descrever o comportamento mais geral da situação da pobreza no país.Em seguida, procura-se destacar os principais aspectos da metamorfose da pobreza no Brasil. Por fim, informa-se que a medida da pobreza absoluta no Brasil tem como critério o conjunto de indivíduos com rendimento per capita de até meio salário mínimo mensal em termos reais, enquanto a taxa de pobreza revela a proporção de pobres em relação ao total da população. 


\section{Comportamento recente da pobreza no Brasil}

A evolução da pobreza no Brasil sofreu uma importante inflexão na tendência de queda que se verificava desde o início do ciclo da industrialização nacional. Embora o país tenha convivido com a pobreza contaminando parcela importante da população urbana, havia o movimento de redução da proporção de pobres no total da população frente ao elevado ritmo de crescimento da economia nacional e, por conseqüência, aumento rápido do nível de emprego, sobretudo assalariamento formal, e do rendimento domiciliar per capita.

A partir de 1980, com a interrupção do ciclo de industrialização nacional, o Brasil interrompeu a tendência de redução significativa da pobreza. De fato, entre 1970 e 1980, a taxa de pobreza caia ao ritmo de 3,2 \% ao ano, enquanto entre 2005 e 1980, a diminuição da proporção de pobres em relação ao total da população desacelerou-se para somente $0,98 \%$ ao ano.

Em síntese, pode-se constatar que nos últimos 35 anos, a taxa de pobreza no Brasil caiu, invariavelmente, 0,36 ponto percentual para cada elevação de um ponto percentual do PIB (Produto interno bruto). Quando a economia nacional crescia quase $9 \%$ em média ao ano, como na década de 1970, a taxa de pobres no país foi reduzida mais rapidamente que a partir de 1980, posto que o ritmo de expansão médio anual da produção nacional regrediu para apenas e tão somente $2,7 \%$ ao ano.

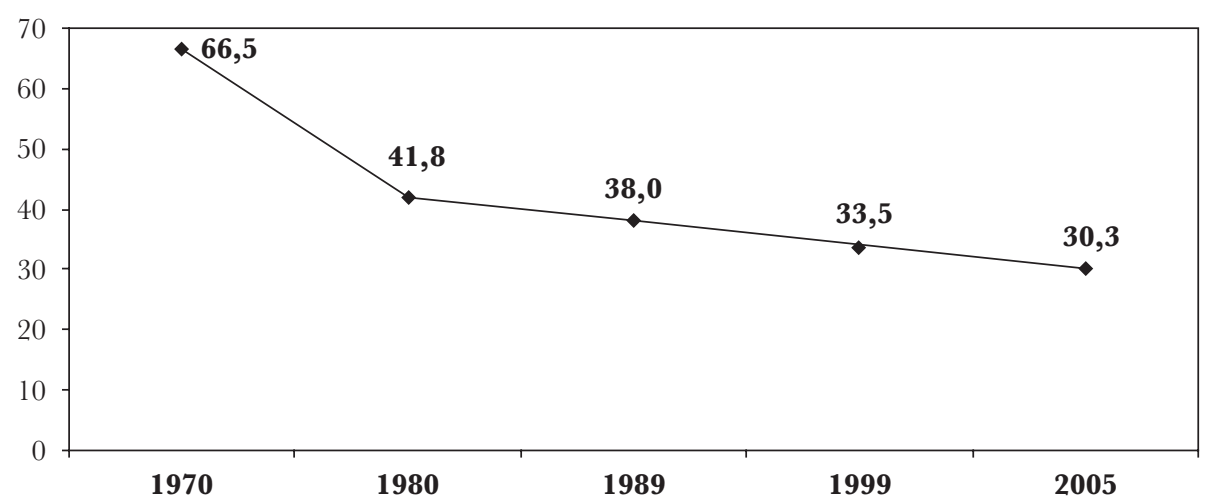

Fonte: IBGE - PNAD (elaboração própria).

Gráfico 1. - Brasil : taxa de pobreza absoluta da população (em \%)

Frente ao contexto de semi-estagnação da economia nacional, ocorreu, por conseqüência, a elevação do desemprego e a precarização generalizada das ocupações. A situação não se tornou ainda mais desfavorável devido aos avanços nas políticas sociais, em grande medida proporcionada pela Constituição de 1988, que terminou implicando a positiva expansão do gasto social.

\section{Metamorfose da pobreza no Brasil}

Com as radicais mudanças no comportamento da economia nacional, que passou pela abertura comercial, financeira e produtiva desde de 1990, passou a se 
constatar uma importante metamorfose na pobreza brasileira. Em primeiro lugar, nota-se que a diminuição da pobreza nacional esteve atrelada à redução de pobres nas áreas não-metropolitanas do país.

A taxa de pobreza caiu $25 \%$ nas áreas não metropolitanas entre 1989 e 2005, enquanto nas regiões metropolitanas a redução da pobreza foi de apenas 3,3\%. No país como um todo a taxa de pobreza foi reduzida em 20,3\% no mesmo período de tempo.

Diante disso, observa-se que a estabilidade monetária contribuiu para diminuir a pobreza, conforme observado a partir da implementação do Plano Real. Mas foi fundamentalmente o movimento impulsionado pela Constituição de 1988 de ampliação do gasto social (previdência social, saúde e educação) e de descentralização dos recursos da educação, saúde e assistência social que possibilitou o maior impulso favorável à elevação das condições de vida, sobretudo nas áreas não-metropolitanas do país.

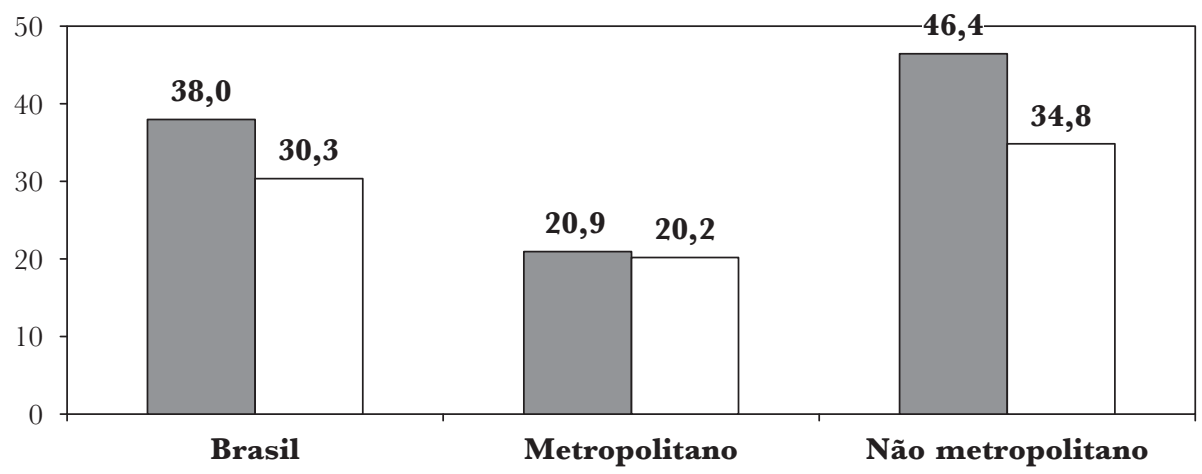

$\square \mathbf{1 9 8 9} \quad \square \mathbf{2 0 0 5}$

Fonte : IBGE - PNAD (elaboração própria).

Gráfico 2. - Brasil : taxa de pobreza absoluta da população (em \%)

Isso parece se confirmar na medida em que se analisa a situação da pobreza segundo a condição de atividade da população. Comparando-se a evolução da taxa de pobreza entre 1989 e 2005, verifica-se que ela mais reduziu nos segmentos inativos, com queda de $22,7 \%$ para os inativos com mais de 10 anos de idade e de 20,3\% para inativos de até 10 anos de idade.

Esses dois segmentos de inativos foram beneficiados diretos das inovações de políticas sociais derivadas da Constituição federal de 1988. Para os inativos de mais idade, destacam-se os exemplos da ampliação de cobertura da previdência e assistência social, da Lei orgânica da assistência social, entre outras, enquanto para os inativos de menor idades ressaltam-se as medidas vinculadas à garantia de renda, como o Peti (Programa de erradicação do trabalho infantil) e os variados programas de transferência de renda vinculados à educação.

Já para o conjunto da população ativa, coube ao mercado de trabalho oferecer condições de renda e ocupação. Mas no período de 1989 e 2005, o desemprego passou de 1,9 milhão de trabalhadores (3\% da PEA) para 8,9 milhões $(9,3 \%$ 


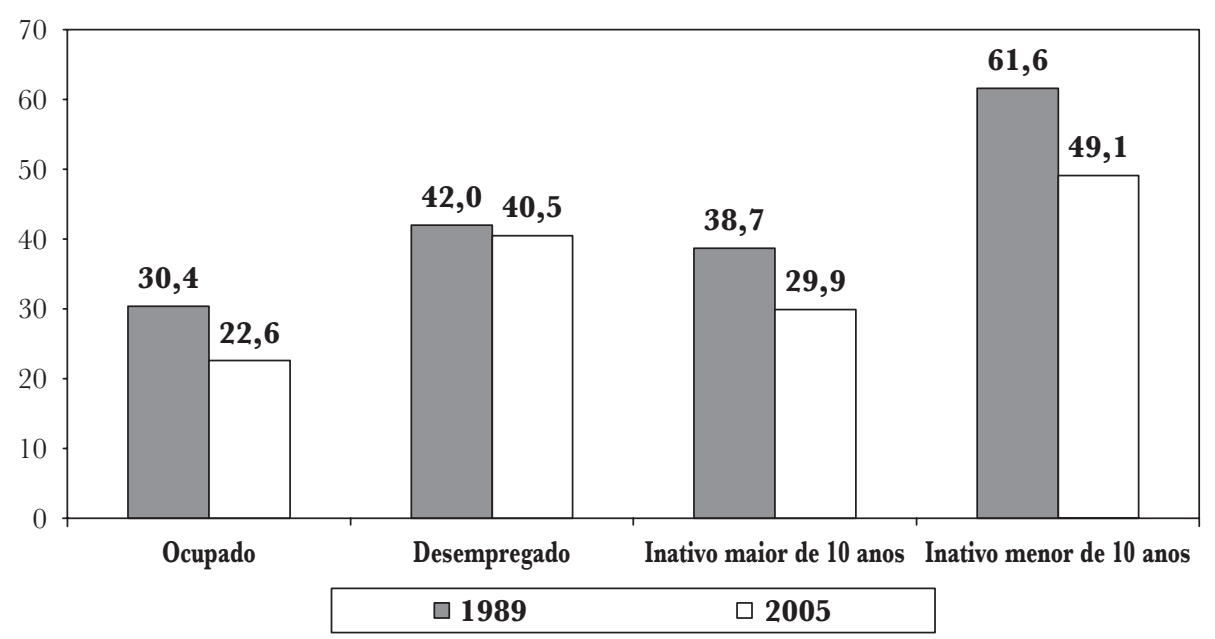

Fonte : IBGE - PNAD (elaboração própria).

Gráfico 3. - Brasil: taxa de pobreza absoluta segundo a Gondição de atividade DA POPUlaÇÃo (em \%)

da PEA), bem como houve piora nas condições e relações de trabalho, ainda que se possam ser destacadas as medidas atenuantes de fortalecimento do salário mínimo e de valorização do seguro desemprego, entre outras modalidades de políticas públicas para o trabalho (qualificação profissional, intermediação de mãode-obra). Nesse ambiente instável do mercado de trabalho, a taxa de pobreza entre os ocupados caiu 25,7\% e entre os desempregados de 3,6\%.

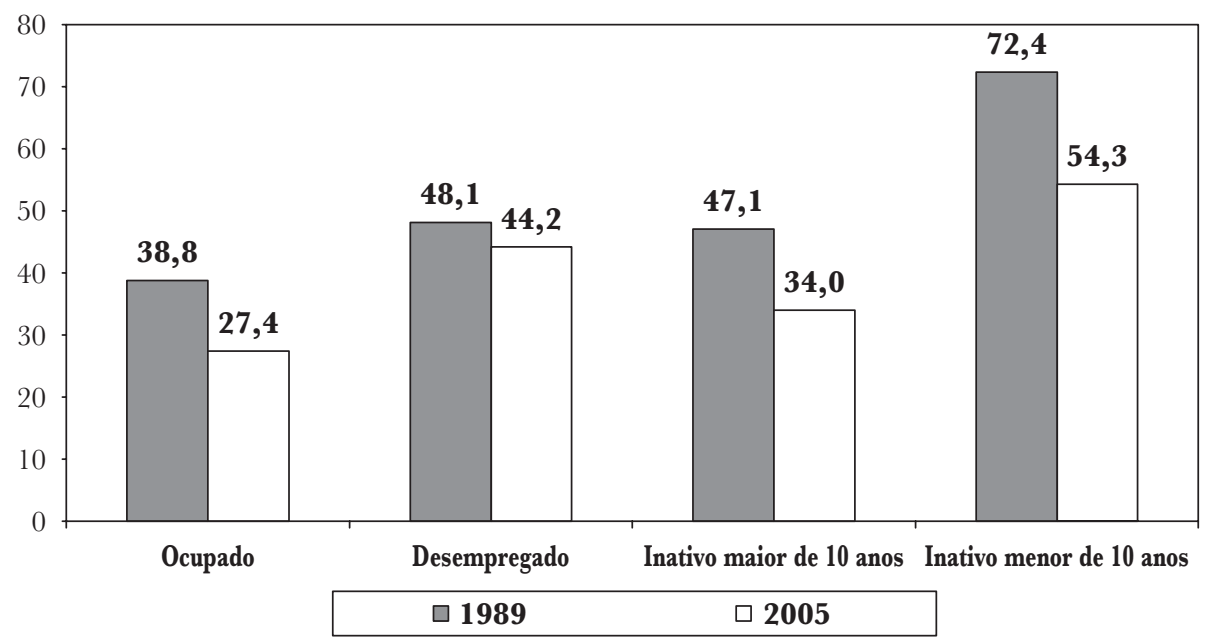

Fonte: IBGE - PNAD (elaboração própria).

Gráfico 4. - Brasil não metropolitano : taxa de pobreza Absoluta SEgundo a Condição DE ATIVidade Da POPUlação (em \%) 
Se considerado o conjunto das regiões não metropolitanas, percebe-se que a queda nas taxas de pobreza segundo a condição de ocupação foi mais intensa. Entre 1989 e 2005, a taxa de pobreza caiu 29,4\% entre os ocupados, 27,8\% entre os inativos com mais de 10 anos de idade, $25 \%$ entre os inativos com menos de 10 anos de idade e 8,1 \% entre os desempregados.

Já em relação às regiões metropolitanas, a redução da taxa de pobreza foi menor e não se deu em todas as condições de atividade. Entre os desempregados, por exemplo, a taxa de pobreza aumentou 2,9\% no período de 1989 e 2005, ao contrário da queda de $14 \%$ entre os ocupados, de 3,5\% entre os inativos de mais idade e de $7 \%$ entre os inativos de menor idade.

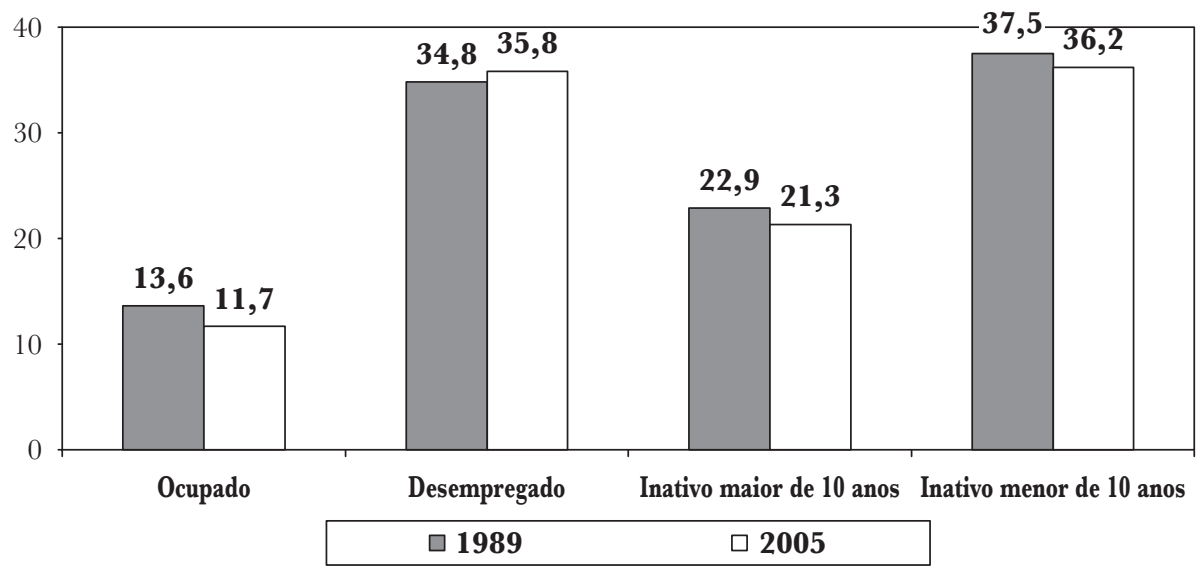

Fonte : IBGE - PNAD (elaboração própria).

Gráfico 5. - Brasil metropolitano: taxa de pobreza absoluta segundo a condição DE ATIVIDADE DA POPULAÇÃO (em \%)

Por conta disso, alterou-se a composição da pobreza segundo condição de atividade. No Brasil como um todo, os inativos perderam participação relativa no total da população pobre (de 56,7 \% para $48 \%$ ), enquanto os ativos aumentaram significativamente (de 43,3\% para $52 \%$ ), sobretudo entre os desempregados.

O mesmo ocorreu nas regiões não metropolitanas. Em 2005, a pobreza estava concentrada entre os ativos, ao contrário de 1989, quando era o conjunto de inativos com o maior peso relativo no total dos pobres.

Nas regiões metropolitanas, o movimento foi o mesmo. O peso do desemprego aumentou significativamente mais, sendo multiplicado por 3,8 vezes entre 1989 e 2005.

Se o critério de análise for o comportamento da pobreza somente entre os ocupados de todo o país, podem ser observadas mudanças interessantes para o mesmo período de tempo. Em todas as posições na ocupação, a condição de empregado foi a única que registrou aumento da taxa de pobreza.

Entre 1989 e 2005, a taxa de pobreza entre os empregados cresceu 53,9\%. Para o mesmo período de tempo, a taxa de pobreza entre os empregadores caiu 44,6 \%, entre os conta-própria caiu 26,7 \% e entre os sem remuneração caiu 20,7 \%. 


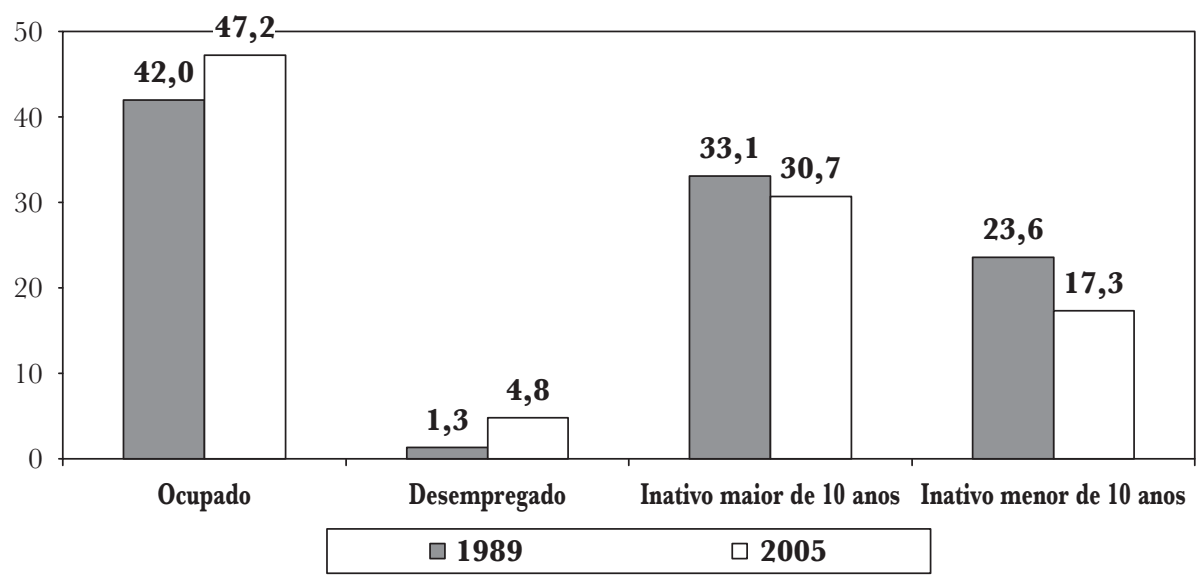

Fonte : IBGE - PNAD (elaboração própria).

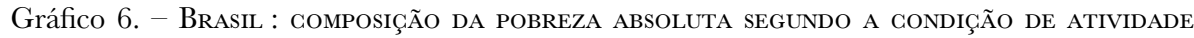
$($ TOTAL $=100 \%)$

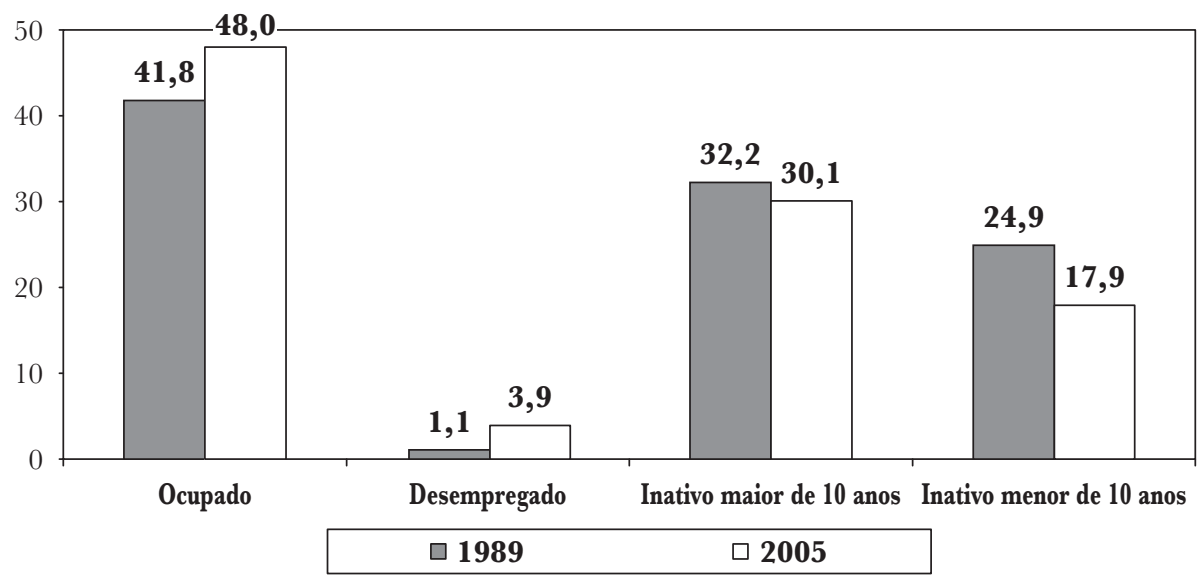

Fonte : IBGE - PNAD (elaboração própria).

Gráfico 7. - Brasil não metropolitano: Gomposição da POBREZa AbSOluta SEGUNDO A CONDIÇÃ̃o DE ATIVIDADE DA POPULAÇÃ̃o (TOTAL $=100 \%$ )

A situação se repete nas regiões não metropolitanas, embora o aumento da taxa de pobreza entre os empregados tenha crescido menos $(35 \%)$. De todo o modo, convém ressaltar que 45,5 \% dos empregados estariam na condição de pobreza em 2005, não muito distante da taxa de pobreza entre os ocupados não remunerados.

O mesmo, no entanto, não se observou no conjunto das regiões metropolitanas, que registrou queda na taxa de pobreza somente entre os ocupados por conta 


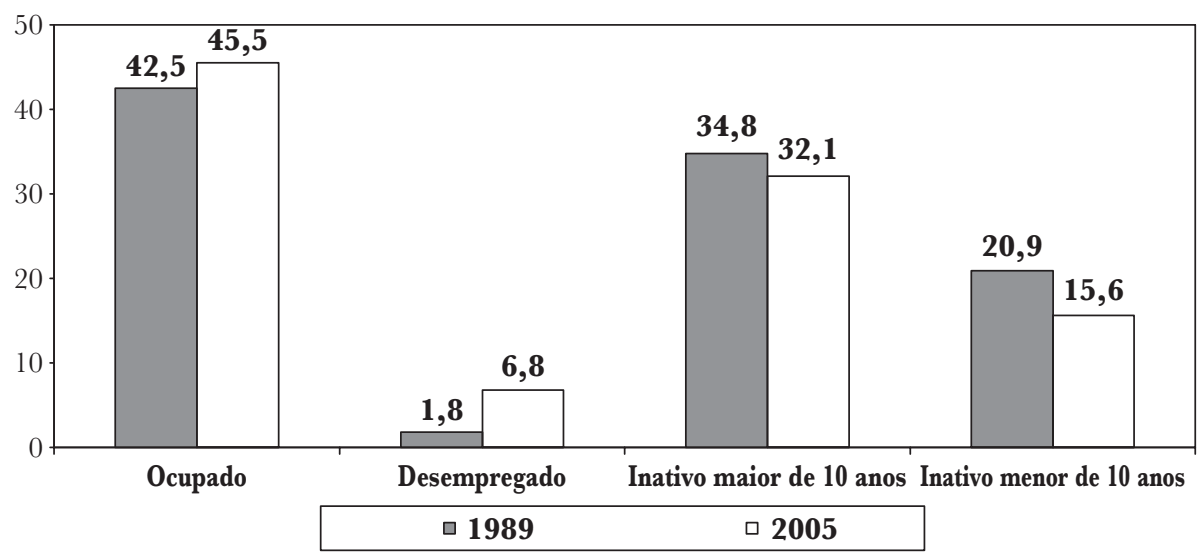

Fonte: IBGE - PNAD (elaboração própria).

Gráfico 8. - Brasil METropolitano : COMPOSIÇÃo DA POBREZA ABSOLUTA SEGUNDO A GONDiçÃo DE ATIVIDADE DA POPULAÇÃo (TOTAL $=100 \%$ )

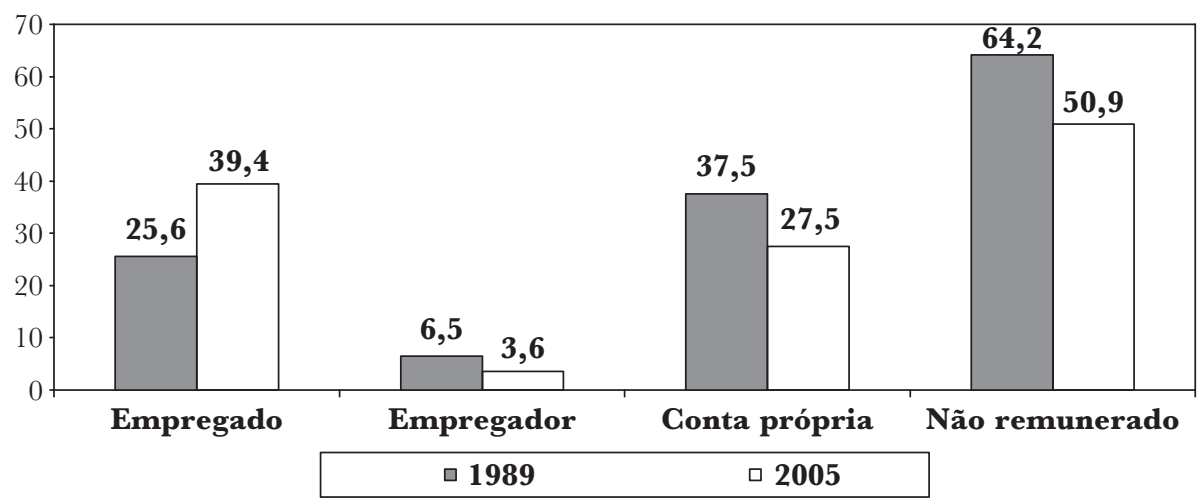

Fonte : IBGE - PNAD (elaboração própria).

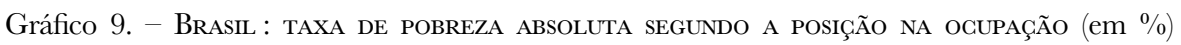

própria. Já e, relação aos empregados, a taxa de pobreza quase dobrou (97 \%) no período de 1989 e 2005, assim como entre os empregadores a taxa de pobreza aumentou 28,6\% e entre os ocupados cresceu 7,2\%.

Em função disso, a taxa de pobreza entre os empregados em 2005 já é superior a de todas as demais posições na ocupação nas regiões metropolitanas. Mais uma especificidade da metamorfose da pobreza no Brasil.

Não sem motivo, a composição do total de pobres ocupados no Brasil sofreu uma importante alteração entre 1989 e 2005. Somente os ocupados por não remunerados aumentaram a sua posição relativa (54,8 \%), enquanto os empregadores registraram o maior decrescimento na sua participação relativa $(22,2$ \%), seguida dos empregados $(14,6 \%)$ e conta própria $(3 \%)$.

Situação idêntica também pode ser constatada no conjunto das regiões não metropolitanas. $\mathrm{O}$ mesmo, no entanto, não ocorreu em relação às regiões metropolitanas. 


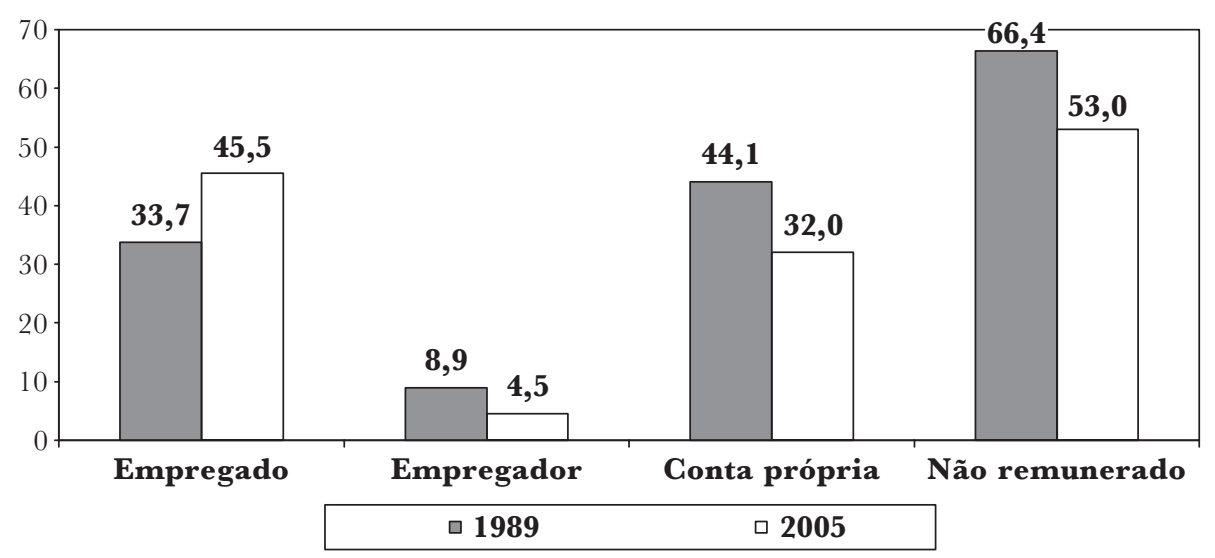

Fonte : IBGE - PNAD (elaboração própria).

Gráfico 10. - Brasil não metropolitano : taxa de pobreza absoluta SEgundo a Posição NA OGUPAÇÃO $($ em \%)

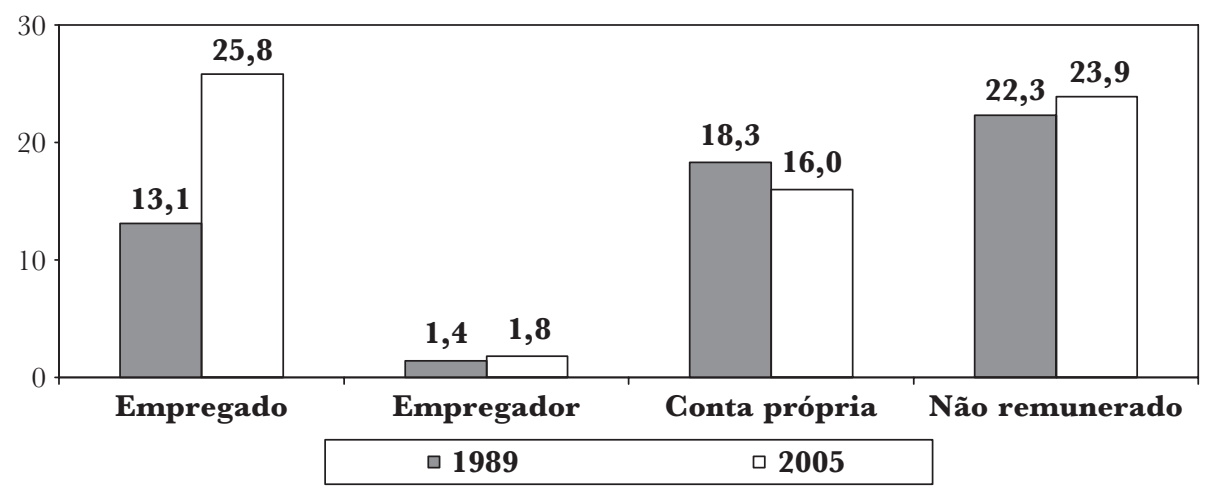

Fonte: IBGE - PNAD (elaboração própria).

Gráfico 11. - Brasil metropolitano: taxa de pobreza absoluta segundo a posição NA OGUPAÇÃo (em \%)

Para o Brasil metropolitano, houve aumento da participação relativa entre as ocupações por conta própria e não remunerado. Para os ocupados na condição de pobreza, o grupo dos empregadores manteve a sua posição relativa, enquanto os empregados reduziram em 12,4\% o seu peso no total dos pobres.

$$
* * *
$$

De acordo com as páginas anteriores, foi possível descrever brevemente os principais aspectos relacionados à alteração na situação da pobreza no período recente. Ao contrário do ciclo de industrialização que era embalado por acelerada expansão da produção e, por conseqüência, de emprego e renda domiciliar per capita, 


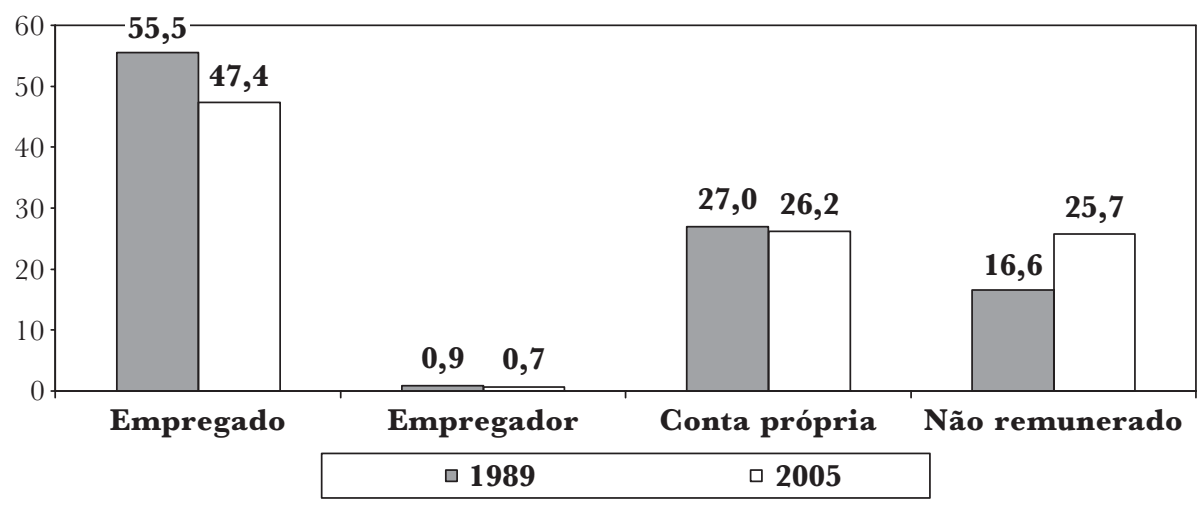

Fonte: IBGE - PNAD (elaboração própria).

Gráfico 12. - Brasil : Gomposição da POBreza Absoluta ENTRE os ogupados (em \%)

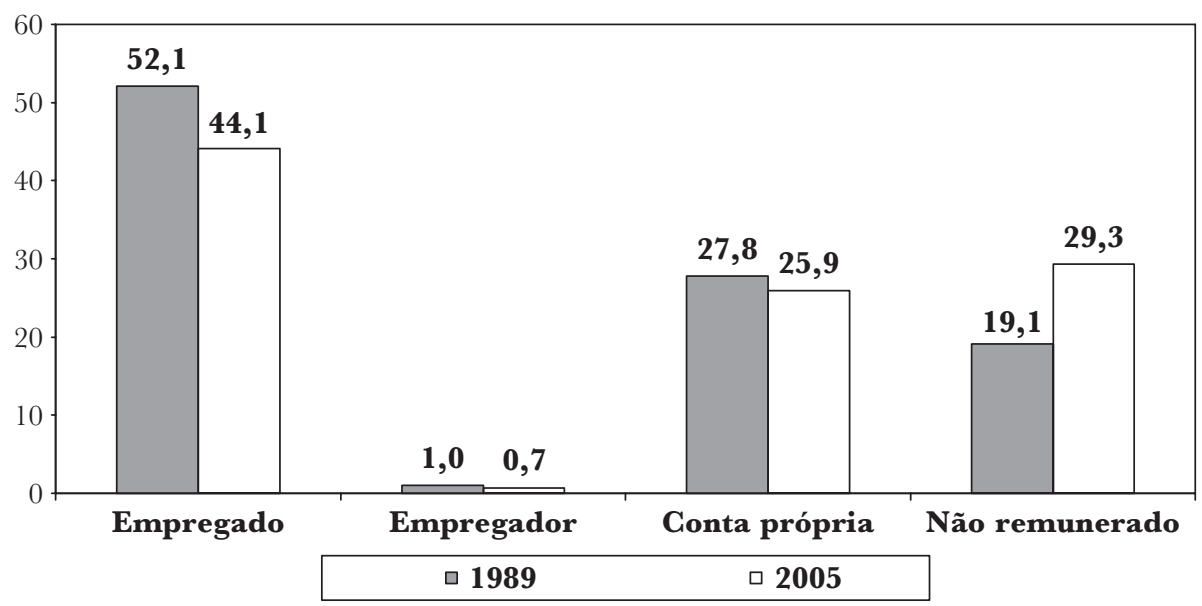

Fonte: IBGE - PNAD (elaboração própria).

Gráfico 13. - Brasil NÃo metropolitano : Gomposição DA POBREZA ABSOlUta ENTRE os OCUPADOS $(\mathrm{em} \%)$

o atual ciclo de financeirização da riqueza asfixia o potencial de crescimento da economia nacional.

Por conta disso, não apenas desacelerou o ritmo de redução na taxa de pobres no país, como tornou mais complexo seu enfrentamento. A partir da década de 1990, a queda na proporção de pobres no total da população se tornou possível pelo avanço do gasto social, estimulado fundamentalmente pela Constituição federal de 1988.

Não há dúvida que estabilização monetária contribuiu para aliviar a situação de pobreza, mas frente ao desempenho desfavorável do mercado de trabalho, o segmento ativo da população tornou-se bem mais vulnerável ao rebaixamento 


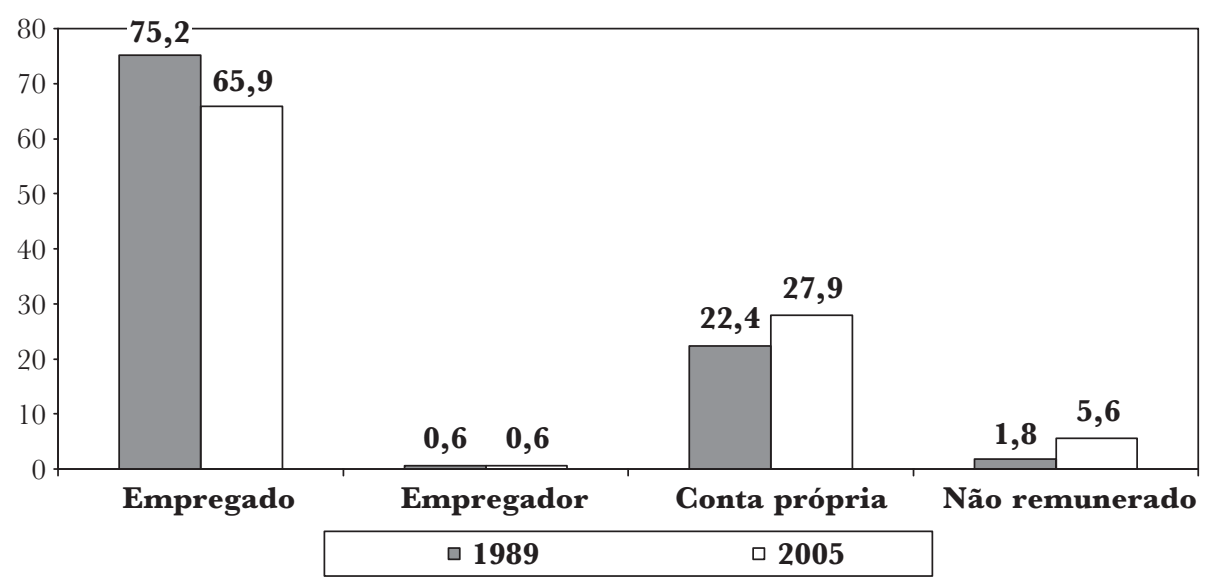

Fonte : IBGE - PNAD (elaboração própria).

Gráfico 14. - Brasil metropolitano: Gomposição Da pobreza absoluta entre os OGUPADOS $(\mathrm{em} \%)$

das condições de vida e trabalho. Mesmo assim, a taxa de pobreza no país declinou.

Mas isso se deve principalmente ao papel ampliado das políticas sociais de atenção tanto aos inativos de mais idade (previdência social, Loas, entre outros) como os inativos de menos idade (Peti e programas de transferencia de renda vinculada à educação). Dessa forma, os inativos deixaram de responder pela maior participação no total dos pobres do país, para se concentrar na população ativa, em especial os desempregados e ocupados precariamente no mercado de trabalho.

Marcio POCHMANN

Universidade Estadual de Campinas (Unicamp) Instituto de Economia (IE)

e Centro de Estudos Sindicais e de Economia do Trabalho (Cesit) <pochmann@eco.unicamp.br> 